IAWA Journal, Vol. 28 (4), 2007: 473-484

\title{
HIGH RESOLUTION SCANNING OF RADIAL STRIPS CUT FROM INCREMENT CORES BY NEAR INFRARED SPECTROSCOPY
}

\author{
P. David Jones ${ }^{1}$, Laurence R. Schimleck ${ }^{2}$, Chi-Leung So ${ }^{3,4}$, \\ Alexander Clark III $^{5}$ and Richard F. Daniels ${ }^{2}$
}

\begin{abstract}
SUMMARY
Near infrared (NIR) spectroscopy provides a rapid method for the determination of wood properties of radial strips. The spatial resolution of the NIR measurements has generally been limited to sections $10 \mathrm{~mm}$ wide and as a consequence the estimation of wood properties of individual rings or within rings has not been possible. Many different NIR instruments can be used to collect NIR spectra from the surface of radial strips at relatively high spatial resolution and the purpose of this study was to compare wood property calibrations obtained using NIR spectra collected in $5 \mathrm{~mm}$ and $2 \mathrm{~mm}$ sections with several different NIR instruments. We found that calibrations based on spectra collected in $5 \mathrm{~mm}$ sections had good statistics, with those based on the Bruker Vector 22/N spectrometer the strongest. Of the three properties examined (density, microfibril angle and stiffness), density had the weakest statistics. When the spatial resolution was decreased to $2 \mathrm{~mm}$, calibration and prediction statistics were weaker than those at $5 \mathrm{~mm}$. RPD 's were relatively low with the highest being 1.76 for predicted stiffness based on NIR spectra obtained using the ASD Field Spec Pro spectrometer. Based on the low RPD 's, we conclude that none of the instruments examined were suitable for scanning radial strips at a spatial resolution of $2 \mathrm{~mm}$.
\end{abstract}

Key words: Air-dry density, high resolution scanning, microfibril angle, near infrared spectroscopy, stiffness, Pinus taeda, SilviScan.

\section{INTRODUCTION}

Near infrared (NIR) spectroscopy provides a rapid method for the determination of several chemical and physical-mechanical properties of wood. Of particular interest has been the estimation of wood properties of increment cores as NIR provides a nondestructive method for assessing the wood properties of standing trees. A series of studies (Schimleck \& Evans 2002a, b, 2003; Jones et al. 2005a, b), used NIR spectra

1) Department of Forestry, Virginia Polytechnic Institute and State University, Blacksburg, VA 24061, U.S.A.

2) Warnell School of Forest Resources, University of Georgia, Athens, GA, U.S.A.

3) School of Renewable Natural Resources, LSU AgCenter, Baton Rouge, LA, U.S.A.

4) USDA Forest Service, Southern Research Station, Pineville, LA, U.S. A.

5) USDA Forest Service, Southern Research Station, Athens, GA, U.S.A.

*) Corresponding author [E-mail: pdjones@vt.edu]. 
collected in $10 \mathrm{~mm}$ sections from the radial-longitudinal surface of Pinus radiata D. Don (radiata pine) and Pinus taeda L. (loblolly pine) pith-to-bark strips, and demonstrated that air-dry density, microfibril angle (MFA), stiffness (as estimated by SilviScan) and tracheid morphological characteristics (coarseness, specific surface and wall thickness) can all be estimated with sufficient accuracy for the utilization of NIR spectroscopy in tree breeding programs and for resource assessment.

While the estimation of many wood properties at $10 \mathrm{~mm}$ resolution has been successful, it does not make the estimation of wood properties of an individual ring or within rings (for example the properties of earlywood and latewood) possible. Hence the provision of wood property data at higher spatial resolution would be desirable. Two options exist for collecting NIR spectra at higher spatial resolution.

The first option for collecting NIR spectra at high spatial resolution is to cut samples from the tangential surface of increment cores or radial strips and obtain NIR spectra from the tangential surface. Depending on the thickness of the tangential section, reflectance (relatively thick sections) or transmission NIR spectra can be collected, properties within-rings can be estimated and the resolution is sufficiently high to facilitate the estimation of earlywood and latewood properties for all but the narrowest rings. Yeh et al. (2004), Sykes et al. (2005), and Yeh et al. (2005) reported the estimation of alpha-cellulose, lignin, and tracheid coarseness and length using transmission NIR spectra collected from thin wafers cut from $P$. taeda increment cores. Calibration statistics were relatively good and indicated that transmission NIR spectroscopy could provide a method for examining wood property variation at high spatial resolution. However, sample preparation is time consuming as multiple wafers have to be cut using a microtome. An alternative is to cut thicker tangential sections (approximately $2 \mathrm{~mm}$ thick) and collect reflectance NIR spectra from the tangential face. Schimleck et al. (2007) explored this option for P. taeda and obtained calibrations for MFA with $\mathrm{R}^{2}$ that compared well with those reported by Jones et al. (2005a), though the standard errors were greater, which could be expected considering the wide range of the MFA data.

The second option involves decreasing the size of the window used when a diffuse reflectance NIR spectrum is collected (for example to $5 \mathrm{~mm}$ or $2 \mathrm{~mm}$ wide) from the radial-longitudinal surface of a radial strip. Decreasing the size of the window decreases the area of the sample exposed to NIR energy $\left(25 \mathrm{~mm}^{2}\right.$ for a $5 \mathrm{~mm} \times 5 \mathrm{~mm}$ window, compared to $50 \mathrm{~mm}^{2}$ for a $10 \mathrm{~mm} \times 5 \mathrm{~mm}$ window) and can affect the quality of the subsequent NIR spectrum and possibly the calibration obtained using the spectra. Recently, Schimleck et al. (2006) reported air-dry density, MFA and stiffness calibrations for a set of Eucalyptus nitens (Deane \& Maiden) Maiden (shining gum) samples that were based on NIR spectra collected in $5 \mathrm{~mm}$ sections from the radial-longitudinal face of radial strips. The MFA and stiffness calibrations were observed to be weaker than those reported for $P$. radiata and $P$. taeda and did not perform well when used on a separate test set. For the MFA calibration, its poor performance was attributed to the limited MFA range of both the calibration (12.0 to $26.8 \mathrm{deg}$.) and prediction (11.6 to $23.3 \mathrm{deg}$.) sets and it was believed that the MFA calibration would benefit from the inclusion of samples with higher MFA. 
Many different NIR instruments can be used to collect NIR spectra from the radiallongitudinal surface of radial strips at relatively high spatial resolution. The purpose of this study was to compare wood property calibrations obtained using NIR spectra collected in 5 and/or $2 \mathrm{~mm}$ sections with several different NIR instruments.

\section{MATERIALS AND METHODS}

\section{Sample origin}

Samples were collected from Pinus taeda plantations located in Georgia, USA. For each of the three physiographic regions in Georgia (Lower and Upper Costal Plain, and Piedmont), five plantations, ranging in age from 21 to 26 years, with a range of site indices were sampled to represent trees presently being harvested as mature. The calibration set was comprised of 9 breast-height $(1.37 \mathrm{~m})$ increment core samples from three plantations within each region; 1 increment core per site was taken. The prediction set was comprised of 6 breast-height increment cores ( 1 per plantation, 2 plantations per region). The samples were taken from a larger set of increment cores which were the subject of previously published research (Jones et al. 2005a, b).

\section{SilviScan analysis}

A total of 15 radial wooden strips were available for SilviScan analysis; these strips were cut from increment cores using a twin-blade saw. Strip dimensions were $2 \mathrm{~mm}$ tangentially and $7 \mathrm{~mm}$ longitudinally; radial length was determined by the pith-to-bark length of the sample. The radial strips were extracted in warm acetone for 24 hours prior to SilviScan analysis.

Wood properties were measured using SilviScan-1 and -2 (Evans 1994, 1998, 1999). Air-dry density (referred to as density for the reminder of the text) was measured in 50-micron steps using X-ray densitometry. MFA was measured over $1 \mathrm{~mm}$ intervals on SilviScan-2 using scanning X-ray diffractometry. An estimate of wood stiffness (same resolution as MFA) was obtained by combining X-ray densitometry and X-ray diffraction data. All measurements were made in a controlled environment of $40 \%$ relative humidity and a temperature of $20^{\circ} \mathrm{C}$. The high-resolution SilviScan data were averaged over 2 and $5 \mathrm{~mm}$ sections from bark-to-pith for correlation with the NIR spectra.

\section{Near infrared spectroscopy}

NIR diffuse reflectance spectra were collected at two different resolutions, $5 \mathrm{~mm}$ and $2 \mathrm{~mm}$, from the radial longitudinal face of the selected radial strips. Several different instruments were used to collect the NIR spectra; they included an Analytical Spectral Devices (ASD) Field Spec Pro FR spectrometer, a Bruker Vector 22/N FT-NIR spectrometer, a FOSS NIRSystems Model 5000 scanning spectrometer, a FOSS Rapid Content Analyzer-XDS Series spectrometer, and a Spectral Dimensions MatrixNIR Chemical Imaging System. With the exception of the ASD Field Spec Pro and the MatrixNIR instrument, a Teflon mask with a window of $5 \mathrm{~mm}$ wide $\times 5 \mathrm{~mm}$ high or $2 \mathrm{~mm}$ wide $\times 5 \mathrm{~mm}$ high was used to control the area of the wood sample exposed to the NIR beam. A summary of the instruments used is given in Table 1 . 
Table 1. Summary of the NIR instruments used in this study.

\begin{tabular}{|c|c|c|c|c|}
\hline Instrument & $\begin{array}{l}\text { Wavelength range } \\
\text { (spectral resolution) }\end{array}$ & $\begin{array}{l}\text { Spatial resolution } \\
\text { of NIR movements }\end{array}$ & $\begin{array}{l}\text { Method used to } \\
\text { collect spectra }\end{array}$ & $\begin{array}{l}\text { Method used to } \\
\text { move samples }\end{array}$ \\
\hline FOSS 5000 & $\begin{array}{l}1100-2500 \mathrm{~nm} \\
(2 \mathrm{~nm} \text { resolution) }\end{array}$ & $5 \mathrm{~mm}$ and $2 \mathrm{~mm}$ & $\begin{array}{l}\text { Mask to control } \\
\text { beam size }\end{array}$ & Automated stage \\
\hline FOSS XDS* & $\begin{array}{l}400-2500 \mathrm{~nm} \\
(0.5 \mathrm{~nm} \text { resolution })\end{array}$ & $5 \mathrm{~mm}$ and $2 \mathrm{~mm}$ & $\begin{array}{l}\text { Fiber-optic probe } \\
\text { and mask }\end{array}$ & $\begin{array}{l}5 \mathrm{~mm} \text { by hand, } \\
2 \mathrm{~mm} \text { automated }\end{array}$ \\
\hline $\begin{array}{l}\text { Bruker Vector } \\
22 / \mathrm{N}\end{array}$ & $\begin{array}{l}1000-2500 \mathrm{~nm} \\
(0.5 \mathrm{~nm} \text { resolution })\end{array}$ & $5 \mathrm{~mm}$ & $\begin{array}{l}\text { Mask to control } \\
\text { beam size }\end{array}$ & By hand \\
\hline $\begin{array}{l}\text { Spectral dimens. } \\
\text { MatrixNIR** }\end{array}$ & $\begin{array}{l}1250-1650 \mathrm{~nm} \\
(4 \mathrm{~nm} \text { resolution) }\end{array}$ & $5 \mathrm{~mm}$ and $2 \mathrm{~mm}$ & $\begin{array}{l}\text { Image of sample } \\
\text { surface }\end{array}$ & Automated stage \\
\hline $\begin{array}{l}\text { ASD Field Spec. } \\
\text { Pro* }\end{array}$ & $\begin{array}{l}350-2500 \mathrm{~nm} \\
(10 \mathrm{~nm} \text { resolution) }\end{array}$ & $2 \mathrm{~mm}$ & Fiber-optic probe & Automated stage \\
\hline
\end{tabular}

* The wavelength range was limited to $1100-2500 \mathrm{~m}$ for the development of calibrations.

** A $2 \times 2 \mathrm{~mm}$ section contained approximately 900 pixels or 900 spectra and it was necessary to average the spectra to give the desired spatial resolution. The data were extracted and managed using MatLab (The MathWorks, Natick, MA, USA) with a program that was written by Robert Cogdill, Duquesne University.

Table 2. The number of spectra in the calibration and prediction sets for each instrument.

\begin{tabular}{lccccc}
\hline & \multicolumn{5}{c}{ Number of species } \\
\cline { 2 - 5 } Instrument & \multicolumn{2}{c}{$5 \mathrm{~mm}$} & \multicolumn{2}{c}{$2 \mathrm{~mm}$} \\
& Calibration & Prediction & Calibration & Prediction \\
\hline FOSS 5000 & 159 & 88 & 399 & 227 \\
FOSS XDS & 157 & 87 & 376 & 195 \\
Bruker & 121 & 87 & - & - \\
MatrixNIR & 151 & 83 & 368 & 203 \\
Field Spec. & - & - & 398 & 228 \\
\hline
\end{tabular}

For each instrument, the number of spectra in the calibration and prediction sets is given in Table 2. Figure 1 compares spectra collected from the same section of a single radial strip for each instrument.

\section{Wood-property calibrations}

Wood property calibrations were developed using the Unscrambler (version 9.2) software package (Camo AS, Norway). The spectra were treated with a second derivative transformation (Savtizky-Golay approach) to reduce base-line variation and truncated to the $1100-2500 \mathrm{~nm}$ region when required, the spectra were then used to create calibrations using partial least square (PLS) regression (Næs et al. 2002). Calibrations were developed with four cross-validation segments. Depending on the sample set used, differing numbers of factors were recommended. For comparative purposes, five factors were used per calibration. 


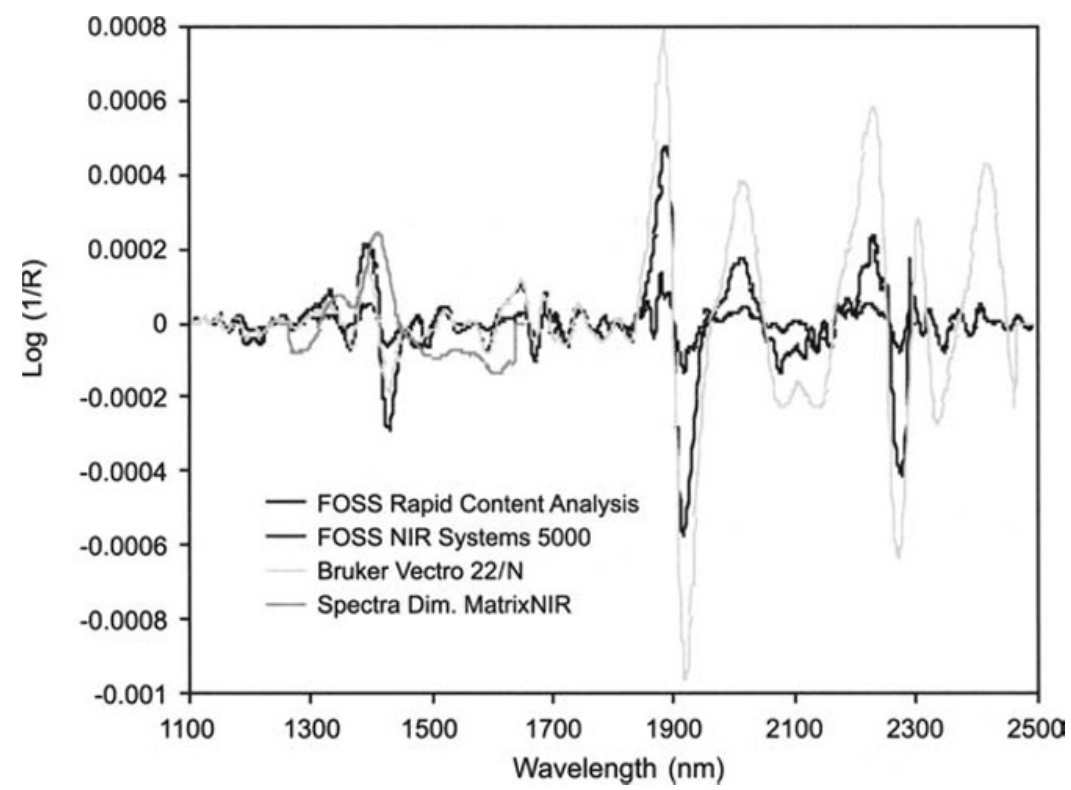

Figure 1. Second derivative NIR spectra collected at $5 \mathrm{~mm}$ using the Bruker Vector 22/N FTNIR spectrometer, the FOSS NIRSystems Model 5000 scanning spectrometer, the FOSS Rapid Content Analyzer-XDS Series spectrometer, and the Spectral Dimensions MatrixNIR Chemical Imaging System. The ASD field spectrometer did not have spectra collected at the $5 \mathrm{~mm}$ resolution. Note: The NIR spectrum shown for the Spectral Dimensions MatrixNIR was multiplied by 0.002 to make it comparable to the NIR spectra collected by the other instruments.

The following calibration statistics were examined:

- the Standard Error of Calibration (SEC) (determined from the residuals of the final calibration);

- the Standard Error of Cross Validation (SECV) (determined from the residuals of each cross validation phase);

- the coefficient of determination $\left(\mathbf{R}^{2}\right)$; and

- the ratio of performance to deviation $\left(\mathrm{RPD}_{\mathrm{c}}\right.$ ) (Williams \& Sobering 1993), calculated as the ratio of the standard deviation of the reference data to the SECV, were used to assess calibration performance. Determination of RPD allows comparison of calibrations developed for different wood properties that have differing data ranges and units - the higher the $R P D_{c}$ the more accurate the data are described by the calibration.

To examine the performance of the calibrations, they were used to predict the wood properties (air-dry density, MFA, stiffness) of the test set samples. The Standard Error of Prediction (SEP) (determined from the residuals of the predictions) was calculated and gave a measure of how well a calibration predicted parameters of interest for a set of samples not included in the calibration set. The predictive ability of the calibrations was assessed by calculating the $R P D_{p}$ (which is similar to the $R P D_{c}$ ) but uses the standard deviation of the prediction set reference data and the SEP. 


\section{RESULTS AND DISCUSSION}

\section{Wood property calibrations}

Increasing the spatial resolution of NIR measurements is a desirable goal as it would allow the estimation of wood properties between and within growth rings. This study compares calibrations built using spatial resolutions of 5 and $2 \mathrm{~mm}$ for several instruments (Table 2). Unfortunately, it was not possible to collect NIR spectra at $5 \mathrm{~mm}$ resolution using the ASD Field Spec Pro and at $2 \mathrm{~mm}$ using the Bruker Vector 22/N spectrometer. Wood property calibrations based on NIR spectra measured at a resolution of $5 \mathrm{~mm}$ using four different NIR instruments are shown in Table 3.

Table 3. Summary of wood property calibrations obtained using NIR spectra collected at $5 \mathrm{~mm}$ resolution using different spectrometers. All calibrations were developed using 5 factors.

\begin{tabular}{llllll}
\hline Instrument & Wood property & $\mathrm{R}^{2}$ & SEC & SECV & RPD \\
\hline FOSS 5000 & Density & 0.82 & 53.3 & 64.4 & 1.95 \\
& MFA & 0.88 & 2.4 & 2.8 & 2.06 \\
& Stiffness & 0.90 & 1.8 & 2.0 & 2.67 \\
FOSS XDS & Density & 0.82 & 53.0 & 61.9 & 2.01 \\
& MFA & 0.79 & 3.2 & 3.5 & 2.04 \\
& Stiffness & 0.88 & 2.0 & 2.2 & 2.59 \\
Bruker & Density & 0.87 & 46.1 & 56.2 & 2.23 \\
& MFA & 0.92 & 1.9 & 2.1 & 3.21 \\
& Stiffness & 0.94 & 1.5 & 1.7 & 3.56 \\
MatrixNIR & Density & 0.62 & 73.0 & 84.7 & 1.40 \\
& MFA & 0.72 & 3.8 & 4.0 & 1.76 \\
& Stiffness & 0.74 & 2.9 & 3.1 & 1.82 \\
\hline
\end{tabular}

Wood property calibrations obtained using the FOSS NIRSystems 5000, the FOSS rapid content analyzer (XDS series), and Bruker Vector 22/N spectrometer all provided strong calibration statistics, but when compared to the calibrations reported by Jones et al. (2005a) only the Bruker Vector 22/N spectrometer provided comparable results. The MFA calibration obtained using the Bruker Vector $22 / \mathrm{N}$ spectrometer is shown in Figure 2. In comparison, the wood property calibrations obtained using the Spectral Dimensions MatrixNIR imaging system were weak.

The calibrations obtained using each instrument at $2 \mathrm{~mm}$ spatial resolution are given in Table 4. Wood property calibrations obtained using NIR spectra collected at $2 \mathrm{~mm}$ resolution were much weaker compared to those obtained using NIR spectra collected at $5 \mathrm{~mm}$ resolution. The strongest calibrations were generally obtained for MFA, the only exception being the Spectral Dimensions MatrixNIR imaging system with the calibration for stiffness giving the best statistics. Overall, the FOSS rapid content analyzer (XDS series) provided the strongest statistics, while the Spectral Dimensions MatrixNIR imaging system gave the weakest. 


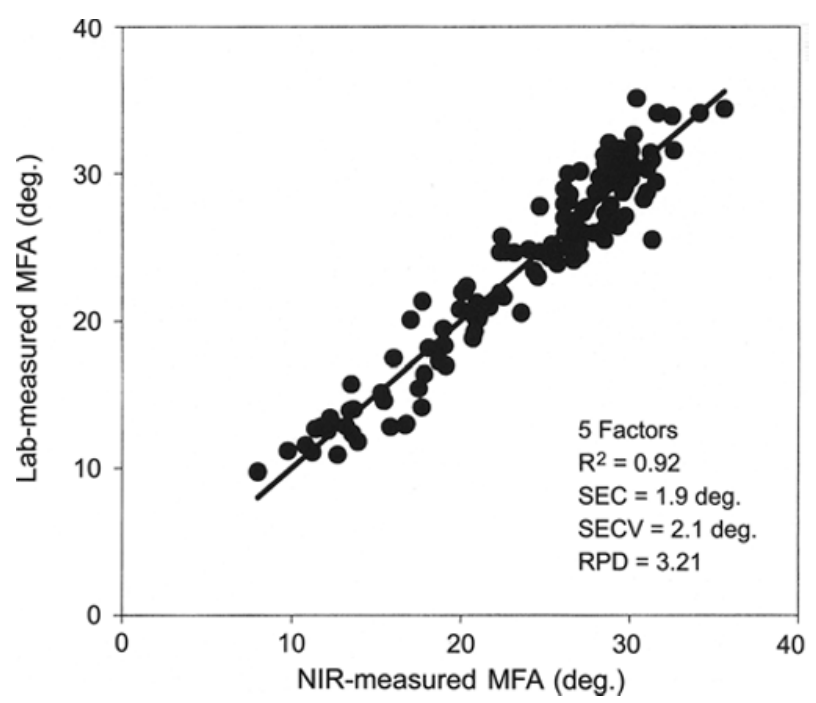

Figure 2. Relationship between measured MFA and NIR-estimated MFA obtained using spectra collected using the Bruker Vector 22/N spectrometer.

Table 4. Summary of wood property calibrations obtained using NIR spectra collected at $2 \mathrm{~mm}$ resolution using different spectrometers. All calibrations were developed using 5 factors.

\begin{tabular}{llllll}
\hline Instrument & Wood property & $\mathrm{R}^{2}$ & SEC & SECV & RPD \\
\hline FOSS 5000 & Density & 0.41 & 144.8 & 174.9 & 1.08 \\
& MFA & 0.77 & 3.6 & 3.7 & 1.98 \\
& Stiffness & 0.64 & 4.0 & 4.3 & 1.54 \\
FOSS XDS & Density & 0.50 & 133.5 & 140.5 & 1.35 \\
& MFA & 0.81 & 3.5 & 3.7 & 2.17 \\
& Stiffness & 0.77 & 3.2 & 3.6 & 1.86 \\
ASD & Density & 0.62 & 116.1 & 132.7 & 1.46 \\
& MFA & 0.71 & 4.0 & 4.4 & 1.68 \\
& Stiffness & 0.75 & 3.3 & 3.7 & 1.83 \\
MatrixNIR & Density & 0.22 & 167.2 & 177.0 & 1.07 \\
& MFA & 0.61 & 4.7 & 4.9 & 1.51 \\
& Stiffness & 0.49 & 4.8 & 5.1 & 1.32 \\
\hline
\end{tabular}

\section{Testing the calibrations}

The wood property calibrations, obtained using NIR spectra collected using a variety of instruments, were tested on NIR spectra obtained from 6 radial strips (1 strip per site). Prediction statistics based on NIR spectra obtained at 5 and $2 \mathrm{~mm}$ spatial resolution are given in Tables 5 and 6 respectively. 
Table 5. Summary of predicted wood properties obtained using NIR spectra collected at $5 \mathrm{~mm}$ resolution using different spectrometers.

\begin{tabular}{lllll}
\hline Instrument & Wood property & $\mathbf{R}_{\mathrm{p}}{ }^{2}$ & SEP & RPD \\
\hline FOSS 5000 & Density & 0.72 & 68.4 & 1.82 \\
& MFA & 0.75 & 3.8 & 1.94 \\
& Stiffness & 0.75 & 3.54 & 1.74 \\
FOSS XDS & Density & 0.72 & 69.5 & 1.79 \\
& MFA & 0.84 & 3.5 & 2.07 \\
& Stiffness & 0.82 & 2.63 & 2.35 \\
Bruker & Density & 0.76 & 61.5 & 2.02 \\
& MFA & 0.80 & 3.57 & 2.05 \\
& Stiffness & 0.85 & 2.85 & 2.17 \\
MatrixNIR & Density & 0.53 & 97.1 & 1.26 \\
& MFA & 0.72 & 4.3 & 1.68 \\
& Stiffness & 0.81 & 2.8 & 2.27 \\
\hline
\end{tabular}

Table 6. Summary of predicted wood properties obtained using NIR spectra collected at $2 \mathrm{~mm}$ resolution using different spectrometers.

\begin{tabular}{lllll}
\hline Instrument & Wood property & $\mathrm{R}^{2}$ & SEP & RPD \\
\hline FOSS 5000 & Density* & 0.36 & 145.8 & 1.24 \\
& MFA* & 0.59 & 5.2 & 1.44 \\
& Stiffness* & 0.59 & 4.5 & 1.41 \\
FOSS XDS & Density & 0.34 & 167.4 & 1.08 \\
& MFA & 0.69 & 5.8 & 1.25 \\
& Stiffness & 0.59 & 5.3 & 1.31 \\
ASD & Density & 0.55 & 122.1 & 1.47 \\
& MFA & 0.65 & 4.5 & 1.64 \\
& Stiffness & 0.70 & 3.95 & 1.76 \\
MatrixNIR & Density & 0.26 & 160.8 & 1.11 \\
& MFA & 0.48 & 6.03 & 1.21 \\
& Stiffness & 0.53 & 4.78 & 1.45 \\
\hline
\end{tabular}

* 3 factors were used, not 5 , as the prediction error was significantly lower.

At $5 \mathrm{~mm}$ resolution, the predictive performance of calibrations based on NIR spectra collected using the FOSS rapid content analyzer (XDS series) fitted with a fiber-optic probe and the Bruker Vector 22/N spectrometer was similar (Fig. 3); however, both provided statistics weaker than those reported by Jones et al. (2005a). The predictive statistics for the FOSS NIRSystems 5000 spectrometer and the Spectral Dimensions MatrixNIR imaging system were inferior to the FOSS XDS and the Bruker instruments, with the Spectral Dimensions MatrixNIR imaging system giving a particularly low $R_{p}{ }^{2}$ (0.53) for density. 


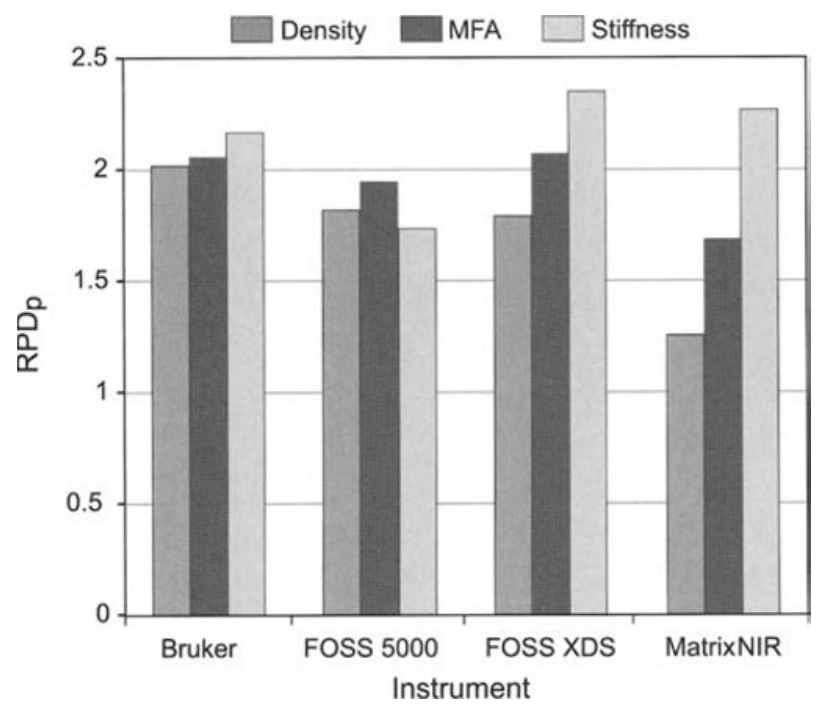

Figure 3. Summary of RPDp obtained for each wood property using NIR spectra obtained at $5 \mathrm{~mm}$ resolution using different spectrometers.

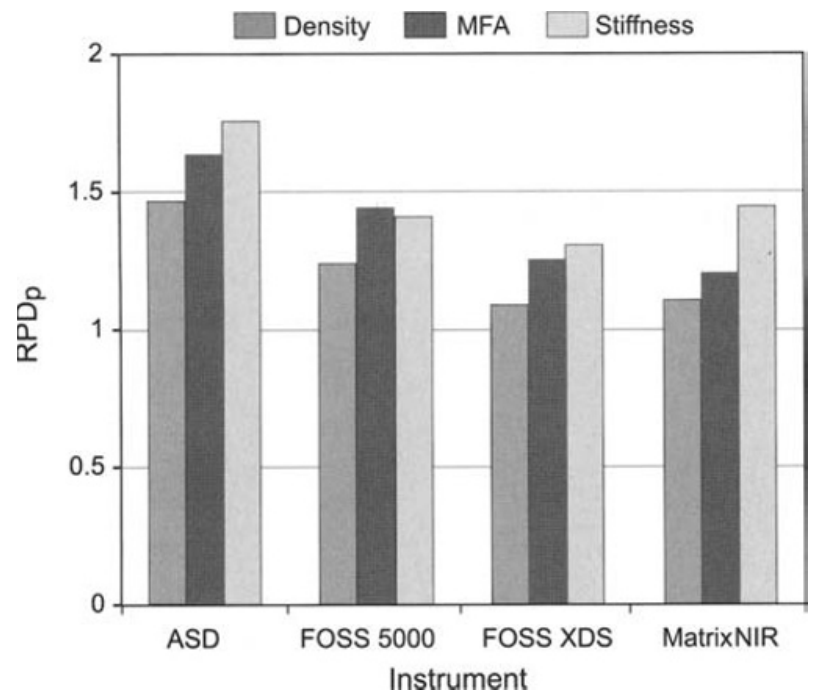

Figure 4. Summary of RPDp obtained for each wood property using NIR spectra obtained at $2 \mathrm{~mm}$ resolution using different spectrometers.

At a spatial resolution of $2 \mathrm{~mm}$, calibrations based on NIR spectra collected using the ASD Field Spec Pro spectrometer gave the strongest predictive performance; however, $R P D_{p}$ 's were relatively low with the highest being 1.76 for predicted stiffness. RPD 's were below 1.5 for the other instruments regardless of the property examined (Fig. 4). Errors were particularly high for predictions of density. The large errors for 


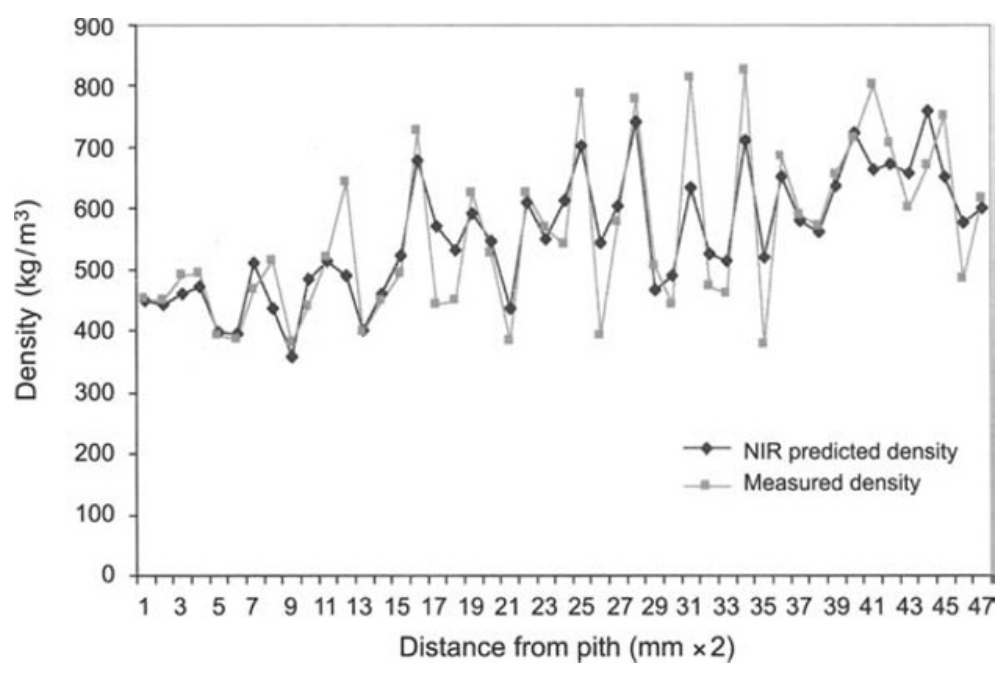

Figure 5. Pith to bark variation in measured density and predicted density for NIR spectra collected using the ASD Field Spec Pro spectrometer at a spatial resolution of $2 \mathrm{~mm}$.

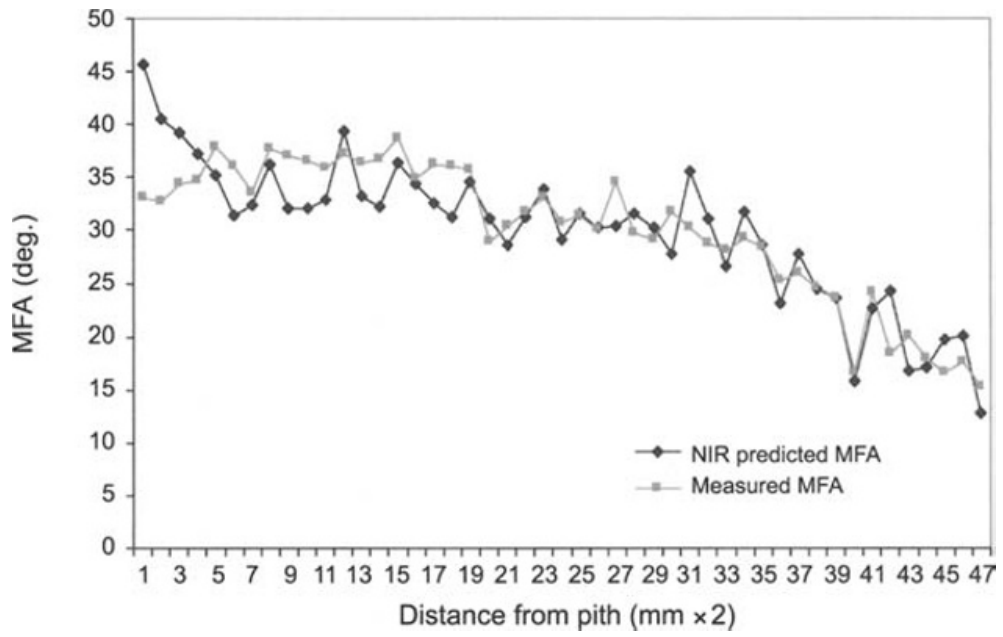

Figure 6. Pith to bark variation in measured MFA and predicted MFA for NIR spectra collected using the ASD Field Spec Pro spectrometer at a spatial resolution of $2 \mathrm{~mm}$.

density have occurred because NIR failed to accurately predict the highest densities for a given core (Fig. 5) and could not follow the abrupt density fluctuations measured using SilviScan. For MFA, and a lesser degree stiffness, the extreme variation observed for density does not occur and the prediction errors are smaller. A plot showing the pith to bark variation of predicted MFA for a single core (same as that shown in Figure 5) based on NIR spectra collected using the ASD Field Spec Pro spectrometer is shown in 
Figure 6. Figure 6 demonstrates that variation in the MFA data is relatively small compared to variation in the density data and NIR predictions of MFA match measured MFA well. Spectra collection with the ASD Field Spec Pro spectrometer did not use a mask. One possibility for the smaller fluctuations may be a larger than expected spot size leading to signal overlap between measurements.

Table 7. Summary of the advantages and disadvantages of each NIR instrument for scanning radial strips.

\begin{tabular}{|c|c|c|}
\hline Instrument & Advantages & Disadvantages \\
\hline FOSS 5000 & $\begin{array}{l}\text { Good quality spectra }(1100-2500 \mathrm{~nm}) \\
\text { Robust, adaptable }\end{array}$ & $\begin{array}{l}\text { Mask required to scan strips } \\
\text { Quality of spectra poor when area } \\
\text { scanned }<5 \mathrm{~mm} \text { wide }\end{array}$ \\
\hline FOSS XDS & $\begin{array}{l}\text { Focused beam } \\
\text { High resolution spectra }(0.5 \mathrm{~nm}) \\
\text { Robust, adaptable }\end{array}$ & $\begin{array}{l}\text { Trigger to activate } \\
\text { Wavelengths }>2300 \mathrm{~nm} \text { noisy }\end{array}$ \\
\hline Bruker Vector $22 / \mathrm{N}$ & $\begin{array}{l}\text { High energy beam } \\
\text { High resolution spectra }(0.5 \mathrm{~nm}) \\
\text { Easy to locate beam }\end{array}$ & $\begin{array}{l}\text { Test std. on regular basis } \\
\text { Softward difficult to use } \\
\text { Sensitive to static }\end{array}$ \\
\hline MatrixNIR & $\begin{array}{l}\text { High res. }\left(1 \text { pixel }=0.004 \mathrm{~mm}^{2}\right) \\
\text { Can increase resolution of spectra } \\
2 \mathrm{D} \text { scan of surface produced }\end{array}$ & $\begin{array}{l}\text { Difficult to manage spectra } \\
\text { Pixel size can vary } \\
\text { Limited wavelength range }\end{array}$ \\
\hline Field Spec. & $\begin{array}{l}\text { Rapid acquisition of spectra } \\
\text { Wide wavelength range } \\
\text { No mask required }\end{array}$ & $\begin{array}{l}\text { Diff. to ID start point on sample } \\
\text { Spot size must be known } \\
\text { Wavelengths }>2300 \text { nm noisy }\end{array}$ \\
\hline
\end{tabular}

\section{Comparison of instruments}

Each instrument also had a number of advantages and disadvantages with reference to scanning radial strips and a summary of each instrument is given in Table 7.

The specific design features of each instrument are directly related to the ultimate end user of the instrument and what will best suit their individual needs. For the examination of wood properties of radial strips, the research is in its infancy and we have had to adapt instruments to fit our needs. As a consequence, existing NIR instruments do not meet the specialized requirements to measure the wood properties of radial strips at high spatial resolution. Of the instruments examined, the simplest to use for collecting NIR spectra from the surface of radial strips is one fitted with a fiber optic probe; however, the relatively large spot size of the probe systems we examined limits spatial resolution. The relatively poor statistics at $2 \mathrm{~mm}$ obtained with the fiber optic probe systems we utilized also suggests that insufficient energy is interacting with the sample. Fiber optic probe systems with increased signal to noise ratio are required to collect high quality NIR spectra at resolutions of $2 \mathrm{~mm}$ (and less if required) and to give wood property calibrations with statistics similar to those reported by Jones et al. $(2005 \mathrm{a}, \mathrm{b})$ for NIR spectra collected at $10 \mathrm{~mm}$ spatial resolution. 


\section{ACKNOWLEDGEMENTS}

Support for this work was provided by the Georgia $\mathrm{TIP}^{3}$ program and is gratefully acknowledged. The authors thank the UGA Wood Quality Consortium for collecting the Pinus taeda samples and for sample preparation. The authors would also like to thank Dr Sandra Kays and Ms Judy Davis (United States Department of Agriculture, Agricultural Research Service, Quality Assessment Research Unit, Athens, GA) for allowing access to their FOSS rapid content analyzer and Bruker Vector 22/N spectrometer and Robert Cogdill (The School of Pharmaceutical Sciences, Duquesne University, Pittsburgh, PA) for his assistance in using the School of Pharmaceutical Sciences Spectral Dimensions MatrixNIR.

\section{REFERENCES}

Evans, R. 1994. Rapid measurement of the transverse dimensions of tracheids in radial wood sections from Pinus radiata. Holzforschung 48: 168-172.

Evans, R. 1998. Rapid scanning of microfibril angle in increment cores by X-ray diffractometry. In: B.G. Butterfield (ed.), Microfibril angle in wood: 116-139. Proc. IAWA/IUFRO International Workshop on the Significance of Microfibril Angle to Wood Quality, Nov. 1997, Westport, New Zealand. University of Canterbury Press.

Evans, R. 1999. A variance approach to the X-ray diffractometric estimation of microfibril angle in wood. Appita J. 52: 283-289, 294.

Jones, P.D., L.R. Schimleck, G.F. Peter, R.F. Daniels \& A. Clark. 2005a. Nondestructive estimation of Pinus taeda L. wood properties for samples from a wide range of sites in Georgia. Can. J. For. Res. 35: 85-92.

Jones, P.D., L.R. Schimleck, G.F. Peter, R.F. Daniels \& A. Clark. 2005b. Non-destructive estimation of Pinus taeda L. tracheid morphological characteristics for samples from a wide range of sites in Georgia. Wood Sci. Technol. 39: 529-545.

Næs, T., T. Isaksson, T. Fearn \& T. Davies. 2002. A user-friendly guide to multivariate calibration and classification. NIR Publications, Chichester. 344 pp.

Schimleck, L.R., G.M. Downes \& R. Evans. 2006. Estimation of Eucalyptus nitens wood properties by near infrared spectroscopy. Appita J. 59: 136-141.

Schimleck, L.R. \& R. Evans. 2002a. Estimation of wood stiffness of increment cores by near infrared spectroscopy: the development and application of calibrations based on selected cores. IAWA J. 23: 217-224.

Schimleck, L.R. \& R. Evans. 2002b. Estimation of microfibril angle of increment cores by near infrared spectroscopy. IAWA J. 23: 225-234.

Schimleck, L.R. \& R. Evans. 2003. Estimation of air-dry density of increment cores by near infrared spectroscopy. Appita J. 56: 312-317.

Schimleck, L.R., E. Sussenbach, G. Leaf, P.D. Jones \& C.L. Huang. 2007. Microfibril angle prediction of Pinus taeda wood samples based on tangential face NIR spectra. IAWA J. 28: $1-12$.

Sykes, R.W., B. Li, G. Hodge, B. Goldfarb, J. Kadla \& H.-m. Chang. 2005. Prediction of loblolly pine wood properties using transmittance near-infrared spectroscopy. Can. J. For. Res. 35: 2423-2431.

Williams, P.C. \& D.C. Sobering. 1993. Comparison of commercial near infrared transmittance and reflectance instruments for the analysis of whole grains and seeds. J. Near Infrared Spectrosc. 1: $25-33$.

Yeh, T.F., H.-m. Chang \& J.F. Kadla. 2004. Rapid prediction of solid wood lignin content using transmittance near-infrared spectroscopy. J. Agric. Food Chem. 52: 1435-1439.

Yeh, T.F., T. Yamada, E. Capanema, H.-m. Chang, V. Chiang \& J.F. Kadla. 2005. Rapid screening of wood chemical component variations using transmittance near-infrared spectroscopy. J. Agric. Food Chem. 53: 3328-3332. 